\title{
CIRPÉE
}

Centre interuniversitaire sur le risque, les politiques économiques et l'emploi

\author{
Cahier de recherche/Working Paper 05-04
}

\section{On Representative Social Capital}

\author{
Charles Bellemare \\ Sabine Kröger
}

Mars/March 2005

\footnotetext{
Bellemare: Département d'économique, Université Laval cbellemare@ecn.ulaval.ca

Kröger: Economic Science Laboratory, University of Arizona s.kroger@econlab.arizona.edu
}

\begin{abstract}
A previous version of this paper circulated under the title "On Representative Trust". Financial support from CentER and CentERdata is gratefully acknowledged. We thank Hanneke Dam, Marcel Das and Corrie Vis of CentERdata for their support throughout the experiment. We are grateful to Oliver Kirchkamp, Arthur van Soest, Eric van Damme, Jan Magnus, Pierre-Carl Michaud, Wieland Müller, Karim Sadrieh, Jan Potters, Matthias Sutter, Ernst Fehr, Martin Dufwenberg, James Cox and Yann Bramoullé for helpful comments. Useful comments were made by participants at the NAKE Research Day in Amsterdam, the ENDEAR Workshop in Jena, the ESA European Meeting in Strasbourg and Erfurt, the Max-Planck-Institute in Jena, the CIRANO in Montréal, the DIW in Berlin, the ENTER Jamboree 2003 meeting and the Social Capital Workshop in Tilburg, the Spring Meeting of Young Economists in Leuven, the Economics seminar in Maastricht, Zürich, and Québec. The second author gratefully acknowledges financial support by the Deutsche Forschungsgemeinschaft, SFB Transregio 15, ("Governance and Efficiency as Economic Systems"), Humboldt Universität zu Berlin, and the EU-TMR ENDEAR Network grant (FMRX-CT98-0238). The usual disclaimer applies.
\end{abstract}




\begin{abstract}
:
This paper analyzes data for a random sample drawn from the Dutch population who reveal their capacity to provide and sustain social capital by their propensity to invest and reward investments by means of an economic experiment. We have three main results. First, we find that heterogeneity in behavior is characterized by several asymmetries - men, the young and elderly, and low educated individuals invest relatively less, but reward significantly more investments. Second, higher expected levels of investments have a positive and significant effect on the level of investments themselves, corroborating the presence of social norms. Third, we compare our results with a laboratory experiment conducted with a student sample. We find that the student sample provides a lower bound of the population level of social capital.
\end{abstract}

Keywords: Social Capital Investments, Social Norms, Experiment, Representative Sample

JEL Classification: Z13, C90, C10, D39 


\section{Introduction}

Most social relations are governed by implicit informal agreements rather than explicit contracts. Even in the later case, contracts are often incomplete, which gives rise to strong incentives to act against the interests of other parties. Institutional economists (e.g., North, 1990; Williamson, 1985) have argued that differences in the costs to enforce contracts translate into cross-country differences in the performance of organizations and economic growth.

Trust, trustworthiness, the propensity to rewarding others who trust (positive reciprocity), and self-enforcing norms of behavior allow trades between two agents to be completed and enforced informally, with lower transactions costs than required by complex contracts. It is now well accepted that social capital rests on these primitives of economic agents (e.g., Bowles and Gintis, 2002). An important body of empirical evidence supports an important link between social capital and economic performance. Using trust as a proxy for social capital, Zak and Knack (2001) for example find that countries with high measured trust have higher economic growth, while La Porta, de Silanes, Schleifer, and Vishny (1997) find that the cross-country variation in levels of trust explains a sizeable portion of the cross-country variation in organizational performance.

These cross-country variations in social capital have been estimated using samples of countries whose social and economic compositions differ greatly, suggesting an important link between the level of social capital in a given society and the economic and social composition of its population. At a micro level, this suggests that the heterogeneity of supply of social capital across individuals within a society may 
well be related to individual differences in socio-economic characteristics and social norms of behavior.

The empirical question we address in this paper is to measure how variations in social norms, economic and social characteristics of individuals affect their propensities to provide and sustain social capital. In order to perform our measurements, we combine the strengths of survey and experimental methods by having a large representative sample of the Dutch population play a computerized version of the two player game similar to that presented by Berg, Dickhaut and McCabe (1995) (henceforth BDMc). The structure of the game allows concerns for social efficiency and motives of trust, trustworthiness, positive reciprocity, and altruism to emerge from the players' decisions. In this game, two players are given an equal endowment, with one player randomly assigned to the role of a sender, and the other player assigned to the role of a responder. The sender must decide how much to invest from his endowment. This amount is doubled and transferred to the responder, who must choose how much of his total wealth, i.e., the amount received plus his endowment, should be returned to the sender. It is easy to see that investments are socially desirable in this game as they increase the overall social surplus. An element of trust is involved as senders bear a risk that responders return nothing. Trustworthiness and reciprocity are involved as responders have the possibility to reward trust placed by senders. Moreover, senders and responders may also invest or return, regardless of the action of the other player, out of pure altruism (see e.g., Cox, 2004).

In concentrating on these aspects of social capital, we do not mean to suggest that other dimensions - such as individual levels of involvement in communities, or 
individual efforts to build and maintain social ties - are unimportant in the larger scheme of social capital. ${ }^{1}$ Rather, they are not objects of our enquiry.

Nevertheless, relating social preferences to socio-economic characteristics can shed insights on the provision of social capital across communities. In most instances, individuals are not randomly assigned to the communities they live in but instead self-select themselves into their communities, presumably based to some extent on their socio-economic characteristics. It is not necessarily the case that the community which has the highest propensity to make social capital oriented investments also has the highest incentives to do so. To see this, let us consider two communities which differ in terms of the background characteristics of their members. It may be that the characteristics of the individuals in the first community are such that they have a higher willingness to invest than the individuals in the second community, but that the individuals in the second community have a higher propensity to reward investments, and hence provide better incentives to invest. In such a case, the asymmetric response is a direct consequence of the fact that individuals who have a relatively higher propensity to invest do not necessarily have a higher propensity to reward investments.

The existence of such asymmetries may seem puzzling as it is commonly believed that the decisions of both parties in the investment game capture amongst others motives of trust, trustworthiness, and altruism. This suggests that individ-

\footnotetext{
${ }^{1}$ See Glaeser, Laibson, and Sacerdote (2002) for empirical evidence on the correlates of community involvement. Carpenter, Daniere, and Takahashi (2004) present evidence from a field experiment in Asia suggesting that trust and trustworthiness are significantly correlated with community involvement.
} 
uals making significantly higher investments should be expected to be those relatively more likely to reward investments. However, evidence in support of asymmetries has recently been found in the lab. Chaudhuri and Gangadharan (2002) and Buchan, Croson, and Solnick (2003) for example find that men invest relatively more than women, while women reward investments significantly more then men. There are a priori no reasons to believe that asymmetries could not exist with respect to age, education levels, or income.

Investigation of all the issues mentioned above requires having samples of participants with more heterogeneous socio-economic backgrounds than commonly found in the lab. The combination of a representative sample and an experiment offers a unique opportunity to explore in detail these issues.

A potential alternative to perform our measurements is to draw a representative sample of respondents from a population, and present each of them with one or several questions capturing specific aspects of social capital. Allesina and La Ferrara (2002), for example, investigate how answers to the World Value Survey (hereafter WVS) trust question correlates with observable characteristics. ${ }^{2}$ While this approach has the benefit of being easily implemented both within and across countries, the use of hypothetical questions has been criticized on the basis that respondents' answers do not correlate well with their observed behavior. Glaeser, Laibson, Scheinkman, and Soutter (2000) and Gächter, Herrmann, and Thöni (2004) for example find that answers to this and related survey questions do not correlate with investments made in a public good experiment. In this paper, we will look at whether or not differences in investment behavior across individuals of different

\footnotetext{
${ }^{2}$ See section 2 for the exact phrasing of this question.
} 
gender, age, or any other socio-economic characteristic are robust to using a survey rather than an experimental proxy for social capital.

The paper makes three additional contributions. First, we contrast the behavior of our heterogeneous sample to that of a student sample by repeating our experiment in the laboratory. This allows to investigate whether laboratory experiments with student subjects are informative about the level of social capital in the population as a whole. Whether or not the lab provides information on the population level of social capital is a valuable insight as experiments are more easily conducted in the lab with student samples rather than with representative samples. Comparing the behavior of our representative and laboratory samples can be more generally related to the literature interested in assessing the external validity of lab experiments. The later has generally been tested by comparing the play in the laboratory with the play by more heterogeneous samples, namely newspaper readers (e.g., see BoschDomènech, Montalvo, Nagel, and Satorra, 2002), and specialized samples including professional traders (Haigh and List, 2005) and CEO's (Fehr and List, forthcoming). These studies typically find that the behavior of subjects in the special sample differs from the behavior in the student population. However, they either do not attempt to relate these differences to observable characteristics of subjects or report very few significant correlations (see, e.g., List, 2004; Gächter, Herrmann, and Thöni, 2004). Instead of focusing on a limited number of subgroups of a population, representative samples provide more of the necessary variation in observable characteristics to precisely measure the effect of a change in characteristics on economic behavior. Three noteworthy experiments have recently been run with representative samples. Harrison, Lau, and Williams (2002) use a random sample of the Danish popula- 
tion to investigate the heterogeneity in individual discount rates. Hey (2002) uses the CentERpanel of Tilburg University (more on this panel later on) to draw a random sample of subjects from the Dutch population who make decisions under risk and uncertainty. Fehr, Fischbacher, Rosenbladt, Schupp, and Wagner (2003) present results from an experiment with a random sample of the German population.

Second, the theoretical literature on social norms suggests an important association between own decisions and the subjective expected behavior of others who face similar decisions (see Elster, 1989; Ostrom, 2000). There are, to our knowledge, no empirical studies looking at the relationship between variations in individual subjective social norms and variations in individual investments in social capital in an experimental context. In our game, social norms cannot be inferred from the choice data without imposing a priori strong assumptions on how these norms are formed. One such set of assumptions consists of equating someone's subjective expectation about the behavior of other players in the same role, with the observed sample average of investments. This is similar but not identical to the practice of inferring peer effects in the social interactions literature from the observed behavior in a reference group (see e.g., Brock and Durlauf, 2001). This approach implicitly assumes that individuals who have the same reference group have identical expectations. We take an alternative route, suggested in Manski (1999), of eliciting directly a person's subjective expectations about the average behavior of other individuals in the same role. This approach allows for a greater heterogeneity in expectations as expectations are no longer tied to reference groups. Eliciting subjective expectations raises endogeneity issues, as participants' stated expectations may be correlated with their experimental decisions. We conduct exogeneity tests to investigate this possibility. 
Finally, our approach has the additional advantage over lab experiments of allowing to test for possible bias caused by using subjects selecting themselves in the experiment based on observable or unobservable characteristics which can be correlated with the decisions in the game, a topic on which very little is known. Eckel and Grossman (2000) report evidence suggesting the presence of participation bias in a classroom experiment. Their approach however compares responses of student volunteers to that of pseudo-volunteers who still partly self-select themselves in the experiment. Here, we test for participation bias using non-participants who truly self-select themselves out of the experiment.

Our results can be summarized as follows. First, we find substantial heterogeneity in investment and returns on investment behavior in the Dutch population. The heterogeneity we uncover is characterized by several unexpected asymmetries. In particular, women are found to invest significantly more than men, but reward investments significantly less; low educated individuals invest significantly less but reward investments significantly more than higher educated individuals; the relation between age and investment is inverted U-shape, with a maximum level of investment at 37 years of age, while the relation between reward behavior and age is convex and in many cases even U-shaped, reaching a minimum at the age between 35 and 38 years. Second, we find that behavior of participants in our laboratory sample provides a lower bound on the level of social capital in the population. In particular, amounts invested and returned were substantially lower in the student sample than in the heterogeneous sample. These differences are found to disappear when controlling for the composition effect of both samples, suggesting that economic and social characteristics of participants are sufficient to explain the ag- 
gregate differences across both samples. Thirdly, social norms, i.e., higher prior subjective expectations about the investment levels of other senders, have a significant and positive effect on investment decisions. Fourth, inferences using the WVS survey question are significantly different from those using our experimental measure. Finally, we cannot find evidence of participation bias in any experimental decisions.

The remainder of the paper is organized as follows. Section 2 describes the design of the experiment, the experimental procedure, and our sample. Section 3 presents our experimental results. Section 4 contrasts differences between investment and reward patterns across groups of the population. Section 5 summarizes our results and concludes.

\section{Experiment and Samples}

\section{Survey Experiment}

The recruitment of our representative sample of participants was made by CentERdata, the survey research institute of Tilburg University in the Netherlands. The main activity of CentERdata is to manage and carry out panel surveys through a telepanel: the CentERpanel, consisting of approximately 2000 representative Dutch households. Every Friday, household members of the CentERpanel receive a questionnaire which they are asked to fill in at any time between Friday and Tuesday of the following week. This questionnaire is filled at home either on a computer or on a television set which is connected to a set-up box linking the household to the CentERdata server. In order to keep the sample representative, low income households without a computer or a television set are given the necessary equipment in order 
to complete the weekly questionnaire. ${ }^{3}$

There are many reasons why the CentERpanel is an attractive medium to conduct experiments. First of all, it gives us access to a representative sample of a population. Second, because participants answer questions on a computer or a television set, we are able to replicate as closely as possible the environment of a laboratory experiment, making results more comparable to those of the existing literature. Third, because we communicate with participants via CentERdata, the experiment is double blind as participants were told that they will be anonymously matched and that their identities would not be revealed to the experimenters. Finally, as CentERdata reimburses the weekly telephone costs for answering the questionnaire by crediting CentERpoints $(1$ CentERpoint $=0.01$ Euro, hereafter $\mathrm{CP})$ to their private bank accounts four times a year, our participants are already familiar to payment in fictitious currency. This allows us to use CP as the experimental currency unit and reimburse our participants in a very convenient way.

Our design closely follows the investment game proposed by BDMc. Some practical aspects of using the BDMc design are that it has been found to be robust to several framing effects (Ortmann, Fitzgerald, and Boeing, 2000). In our game, a sender and a responder were both endowed with $500 \mathrm{CP}^{4}$ The sender could send money

\footnotetext{
${ }^{3}$ For a description of the recruitment, sampling methods, and past usages of the CentERpanel see: http:/ /www.centerdata.nl . Children below 16 years of age as well as immigrants are excluded from the panel. The latter group for the reason that their language proficiency in Dutch makes it difficult for them to answer the questions on a weekly basis.

${ }^{4}$ For ease of reading we keep the terms "sender" and "responder" for the different roles. In the experiment we omitted suggestive labels and referred to the person itself or to its opponent as "the matched panel member." Computer screens of the original experiment (in Dutch) are available upon
} 
to the responder from his endowment. We discretized the choice set of the sender to 11 investment possibilities $I \in\{0,50, \ldots, 450,500\}$. The amount sent was doubled by the experimenters and added to the endowment of the responder.

Responders made their choices using the strategy method, by which they were asked to state how much they would return to senders for all 11 possible amounts they could receive. For each amount invested, the maximal amount responders could return was their endowment of $500 \mathrm{CP}$ plus two times the amount invested. The amounts returned were not constrained to be discrete. The element of the vector of responses which corresponded to the actual investment of the sender was chosen to be the effective action and determined the payoff of both participants. The strategy method, dating back to Selten (1967) was chosen to overcome the difficulty of having members of the CentERpanel interact in real time. This method has several additional advantages. First, it facilitates data acquisition as the complete strategy plan for all 11 possible amounts received is elicited. Second, as our game may seem complex to some subjects, the strategy method requires that people thoroughly familiarize themselves with the ramifications of all choices, so that we do not retrieve data from uninformed subjects. ${ }^{5}$

After all participants made their decisions, senders and responders were randomly matched and payoffs were computed based on the decisions of the pair. The request. The translated text of all screens is enclosed in appendix A.

${ }^{5}$ There is weak evidence suggesting that a hot environment triggers stronger responses in two player games. McLeish and Oxoby (2004) find that the play of proposers and responders in the ultimatum game does not significantly differ between a hot environment and an environment where responses were collected using the strategy method. Similar results are reported by Brandts and Charness (2000) for sequential two player games. 
final payoffs were computed as follows: a sender received the initial $500 \mathrm{CP}$ reduced by the amount invested plus the amount received from the responder, while the responder received her initial endowment of $500 \mathrm{CP}$, the amount sent by the sender multiplied by 2 less the amount returned to the sender. ${ }^{6}$

We elicit beliefs of players in our experiment with a series of questions, all of which were asked after players made their decisions in order to circumvent the possibility that belief elicitation induces non-cooperative behavior when asked before the play of the game. ${ }^{7}$ We measure social norms for senders by asking them for their prior subjective expectations of the average amount which will be sent in the experiment. Because responders had to make 11 different decisions, asking for their prior social norms of behavior would have meant asking them to answer 11 subjective expectation questions, one for each of their decisions. Given CentERpanel has an agreement with its survey participants that no more than thirty minutes of their time would be required to answer questions every week, it was not possible for us to elicit prior social norms for responders. Responders were only asked to state how much they thought of receiving from senders. The rationale behind ask-

\footnotetext{
${ }^{6}$ The multiplier represents efficiency gains of the social interaction. Multipliers vary across studies. BDMc for instance use a multiplier of three, whereas Glaeser, Laibson, Scheinkman and Soutter (2000) apply a multiplier of two.

${ }^{7}$ Subjects were not rewarded based on the accuracy of their expectations. There are theoretical grounds suggesting that, assuming subjects are risk neutral and do not distort probabilities, beliefs elicited using the quadratic scoring rule should be more accurate than unpaid elicited beliefs. The empirical evidence seems not very supportive of this. Ortmann, Fitzgerald, and Boeing (2000) find that unpaid senders in their trust game had surprisingly accurate estimates of the average amounts sent by other senders while both Friedman and Massaro (1998) and Sonnemans and Offerman (2001) find insignificant differences between elicited beliefs of paid and unpaid subjects.
} 
ing responders for those beliefs was to investigate whether decisions recorded using the strategy method are consistent with decisions associated with outcomes responders believed would materialize during the play of the game. This concluded the experimental part of the session.

All players were then asked to answer a question about their past experiences with trust

Lifetime trust experience question In the past, when you trusted someone, was your trust usually rewarded or usually exploited?

(Always exploited) $1,2,3,4,5,6,7$ (Always rewarded).

This question will be used to test for the presence of state dependent behavior whereby differences in past experiences with trust may lead to different investment behavior.

Two weeks after the experiment, each participant received feedback information on the outcome of the game and their final payoff which was later credited to their CentER bank accounts. The experiment was conducted in two sessions, in the 31st and the 36th weeks of the calendar year 2002. Individuals contacted had to read an opening screen informing them that they were selected to participate in an experiment conducted jointly by a team of university researchers. A detailed description of the game followed with the mode of payments. Each person was informed that conditional on their participation, they would be randomly assigned to one of the roles and matched to another panel member. The role was revealed once a panel member had agreed to participate. We contacted 541 panel members from which 42 declined to participate. Of the 499 panel members who completed the experiment, 
276 were senders and 223 were responders. ${ }^{8}$

\section{Laboratory Experiment}

The laboratory experiment differed from the survey experiment in the following ways. First, participants were recruited at the campus of Tilburg University, either by email using a list of past participants, distribution of flyers, or advertisement in the campus newspaper. Participants were primarily undergraduates who were mainly studying economics and business administration. Second, we have no information about prospective participants who heard about the laboratory experiment but decided not to participate, a clear disadvantage compared to our survey experiment. Third, the experiment took place at the experimental laboratory of Tilburg University, located on the campus of the university.

In total, 10 sessions were conducted in November and December of 2002. Strong emphasis was placed on keeping participants' identities private information. Upon arrival, participants received a show up fee of 2 Euros and an identification (ID) code which they used as identifier for the experiment. In exchange of their ID-code, each participant collected a sealed envelope containing feedback information and his payoff (in Euros) two weeks after the experiment. This mirrors the delay of payment used with the representative sample. Participants were asked about their demographics and income in a post experimental questionnaire. This questionnaire was a copy of the one used by CentERdata to collect information from its panel

\footnotetext{
${ }^{8}$ Note, that the number of senders exceeds the number of responders. In order to balance the unequal number of players in both roles, 53 responders were randomly assigned twice to a sender. Exactly like all other participants, those responders received payments resulting from only one matching, namely the first.
} 
members. Using the same questionnaire ensured that the information gathered in the lab was perfectly compatible with the information gathered by CentERdata.

In total 100 students participated in the experiment, of which 52 were senders and 48 responders. ${ }^{9}$ None of the persons which registered for the laboratory experiment declined to participate later.

Table 1 gives the explanation of the variables and descriptive statistics of the players in the representative and laboratory samples, sorted by their role in the game. The means of most variables are relatively identical across all groups, regardless of the sample. Two notable differences in the representative sample are the work propensity and age. Non-participants are on average 10 years older than both senders and responders. This age effect is also reflected in a higher labor market retirement frequency and lower work participation.

As we expected, the composition of both samples is very different. We comment here on the more important differences. We find a relatively higher representation of men in the lab sample. ${ }^{10}$ Participants are significantly younger and have lower personal income in the laboratory sample relative to the representative sample. Most participants in the survey sample either have a secondary or training degree as their highest level of education. ${ }^{11}$ This is in contrast to the education levels of laboratory

\footnotetext{
${ }^{9}$ The matching procedure used to deal with the imbalance between the number of senders and responders in the survey experiment was also used in the laboratory experiment.

${ }^{10}$ The gender ratio in the lab mirrors the one of students who are subscribed to business administration and economics. Nol Lebbink, head of the student administration department from Tilburg University supplied us with the information about the ratio of women in those fields of study, which is 0.4 .

${ }^{11}$ CentERdata distinguishes between 9 different education degrees. After consulting CentERdata, we merged those to the following 4 categories: low education (no education (yet), primary edu-
} 
participants who all have a secondary degree which serves as a prerequisite to undergoing university studies. Only a few laboratory participants have had already completed a university or training degree at the time of the experiment. Almost none of them is working compared to more than half of panel members who do.

Catholics and protestants are the two most important religious communities in the representative sample while having no religious affiliation (being atheist) is the modal response in the laboratory sample. ${ }^{12}$ The superior number of reported catholics in the laboratory sample is partly a consequence of the fact that Tilburg University is located in a predominately catholic area in the south of the country.

It is interesting to note that the variances in age and income are significantly smaller in the lab sample, accompanied by practically no variation in levels education, making it difficult to measure age, income and education effects using only the laboratory data.

\section{Participation Decision}

Because we observe the characteristics of individuals in our representative sample who decide not to participate in the experiment, we are able to test for the presence of participation bias. Participation bias could be present if, for example, participants have unobservable predispositions to gamble or systematically different levels of risk aversion. We estimated all our models with an auxiliary participation equation, allowing the unobservable random components of the equations of intercation, special education, other), secondary education (lower secondary education and higher secondary education), training degree (intermediate vocational training and higher vocational training), university degree (university education).

${ }^{12}$ Atheists are the predominant group subsumed in the variable OTHERS in both samples. 
est to be correlated with the unobservable random component of the participation equation, in a manner reminiscent of Heckman (1978). In this setup, unobserved characteristics common to both the experimental decisions and the participation decision would be picked up by the correlations between the unobservable components of the equations of interest and the participation equation. ${ }^{13}$ We found that none of the correlations were statistically significant, indicating the absence of bias driven by individual predispositions towards play in games. ${ }^{14}$ One explanation for the lack of bias may be that the individuals who participate in the CentERpanel are already drawn from a pre-selected sample of individuals motivated to answer questions. Individuals in this sample may thus differ less in terms of unobservable predispositions to participate. This pre-selection problem is however not specific to our approach, but is shared with most non-experimental survey data sets, as well as laboratory experiments where participants are recruited from a mailing pool of past participants.

\section{Experimental Results}

The sample distributions of investments is shown in Figure 1. The distribution of investments in the representative sample is skewed to the left, with more than $30 \%$

\footnotetext{
${ }^{13}$ As exclusion restriction, we use the proportion of questionnaires completed by panel members in the three months which preceded our experiment. This variable affects participation but does not directly affect the experimental measure used in this paper and captures therefore directly the participation propensity of subjects when participation is uncorrelated with financial outcomes (members of the CentERpanel are not paid to participate in the panel).

${ }^{14}$ Estimation results are available upon request to the authors.
} 
of the sample investing half of their endowment (i.e., $250 \mathrm{CP}$ ). In contrast, the distribution of investments made in the student sample has a mode at $0 \mathrm{CP}$, with more than $25 \%$ of the sample investing nothing, while less than $10 \%$ of the sample invest half of their endowment. A Pearson chi square test ( $p$-value $=0.000)$ easily rejects the null that both distributions are the same.

We measure the propensity to reward investments using the return ratio, defined as the amount returned divided by the maximal amount which can be returned, given an amount invested. For a given investment, the maximal amount which can be returned equals the amount invested multiplied by two, plus the experimental endowment of $500 \mathrm{CP}$. Because we use the strategy method, we observe a sequence $\left\{R_{a} \in[0,1] \mid a \in\{0,50, \ldots, 500\}\right\}$ for each responder, where $R_{a}$ denotes the return ratio when receiving an investment of $a \mathrm{CP}$. The main advantage of the return ratio is that it is automatically scaled, which controls for the fact that receivers can send more simply because the total available amount increases with $a$.

We summarize the implications of responders' behavior in Figure 2, where the left and right columns present graphs for the representative and student samples, respectively. The top panels present two return ratio curves. The curve with solid squares represents the sample median return ratio for all 223 responders of the representative sample, and all 48 responders in the student sample for all possible levels of investment. The important feature of these two panels is that the ratios monotonically increase and are concave in the amounts invested.

Existing results on the investment game do not report such a monotonic response behavior (e.g., BDMc; Cox, 2004). One possible explanation for this discrepancy is that the monotonicity we observe is a consequence of using the strategy method, 
which induces responders to sequentially return increasingly higher proportions as the amounts they can possibly receive increases. Without data on responders behavior gathered in an environment of immediate interaction, this possibility cannot be tested. However, some insights can be obtained by comparing the sample median return ratios using the full strategy vector data with the median return ratios using only the element of the strategy vector associated with the investment a responder believed would materialize in the play of the game. Because we are keeping only one element of the strategy vector for each responder, increases in return ratios across two consecutive levels of investment cannot be the result of having the same individuals reporting monotonically increasing return ratios. Results are graphed in the top panels as a curve with solid triangles. ${ }^{15}$ We find that the shape of both curves are similar across all possible levels of investments in both samples, indicating that responders' decisions tend to increase monotonically with the amounts invested.

Does it pay to invest? In order to answer this question graphically, all graphs in the bottom two panels of Figure 2 plot a common set of visual aids. The lower and upper dashed lines of all four graphs plot the return ratios providing investors with a return on investment $(R O I)$ of respectively $R O I=0$ (investors received exactly what they invested) and $R O I=1$ (additionally to the amount sent, investors receive the entire surplus created by sending) for all possible levels of investment $I$. The dotted line plots the return ratios providing proposers and responders with equal monetary payoffs. ${ }^{16}$

\footnotetext{
${ }^{15}$ Outcomes associated with amounts sent of 400 and $450 \mathrm{CP}$ were believed to occur by only 3 and 0 responders respectively, and were not added to the graph.

${ }^{16}$ These ratios are solved as follows. By definition, the $R O I_{I}$ for a level of investment $I$ corresponds to $R O I_{I}=\left(A_{I}-I\right) / I$, where $A_{I}$ denotes the amount returned at that level of investment. The return
} 
The middle panel reports the sample median return ratios for the representative and student samples. The median return ratio for the representative sample follows closely the $R_{I}\left(R O I_{I}=0\right)$ line for the representative sample, but is below this line for investments in excess of $100 \mathrm{CP}$ for the laboratory sample. This indicates that senders have an estimated $50 \%$ probability of making a loss when playing against a random responder from the Dutch population, as opposed to a significantly higher probability when interacting with a responder from the laboratory. ${ }^{17}$

In order to quantify differences in the spread or the return ratio distribution for both samples, we plot the 25th and 75th percentiles of both distributions in the lower panels of Figure 2. We find that the return ratio distribution is more dispersed in the student sample than in the representative sample. In particular, the 25th sample percentile in the representative sample practically coincides with the sample median and with the $R_{I}\left(R O I_{I}=0\right)$ line, indicating that approximately $25 \%$ of the responders compensate investors exactly by returning to them their investment. On the other hand, the 25th percentile in the student sample is both substantially lower ratio $R_{I}$ is defined as $A_{I} /(2 I+E)$, where $2 I+E$ is the maximal amount which can be returned (i.e., twice the investment $I$ plus the endowment $E$ of $500 \mathrm{CP})$. Substituting $A_{I}$ by $R_{I}(2 I+E)$ in the return on investment formula and rearranging, we get $R_{I}\left(R O I_{I}\right)=I\left(R O I_{I}+1\right) /(2 I+E)$, representing the return ratio which is consistent with a return on investment of $R O I_{I}$.

In Figure 2 the dashed lines represent $R_{I}\left(R O I_{I}=1\right)$ and $R_{I}\left(R O I_{I}=0\right)$ for all possible levels of investments I; and the dotted line plots a return ratio consistent with equal monetary payoffs, which for the game at hand is characterized by responders returning three quarters of the amount they receive, i.e., $A_{I}=3 / 4 \cdot 2 I$.

${ }^{17}$ Comparing the median return ratios of the representative sample to those of the student sample using a Mann-Whitney-U test results in $p$-values (for the null hypothesis that medians are the same) which are below 0.001 for for all investment levels. 
than the sample median, and well below the $R_{I}\left(R O I_{I}=0\right)$ line, suggesting again that the probability that senders make losses is greater in the student than in the representative sample.

Several broad patterns emerge from the descriptive analysis of investment and reward behaviors. First, there are considerable investments made in the Dutch pop-

ulation. Second, returns on investments cannot be increased by investing more, a feature which holds for both the representative and laboratory samples. Third, amounts invested and amounts returned are significantly lower in the laboratory sample than in the representative sample.

\subsection{Empirical Results on Investment Behavior}

In this section, we investigate the determinants of investments $I$, an ordinal and discrete variable. Define $I^{*}$ as a proposer's unobservable latent propensity to invest. The mapping between $I^{*}$ and $I$ is given by:

$$
\begin{aligned}
I_{i}^{*} & =x_{i}^{\prime} \beta+\varepsilon_{i} \\
I_{i} & =k \text { if } \quad m_{k-1}<I_{i}^{*} \leq m_{k}, \quad k=0, \ldots, K
\end{aligned}
$$

The index $i$ denotes the individual, $x_{i}$ is a vector of explanatory variables including a constant term, $\beta$ is the vector of parameters of interest, and $\varepsilon_{i}$ is the error term, assumed to be normally distributed $N(0,1)$. The index $k$ represents the category of the discrete amount sent and $K$ the total number of categories. We make the usual normalization $m_{-1}=-\infty, m_{0}=0$, and $m_{K}=\infty$. The thresholds $m_{1}, \ldots, m_{K-1}$ can be seen as nuisance parameters. As can be seen from Figure 1, there were little 
investments from 300 to $450 \mathrm{CP}$, which prevents identification of all threshold parameters. In our empirical application, we merge these categories and estimate by Maximum Likelihood a model with eight outcomes $(K=7)$.

The first two specifications of Table 2 present parameter estimates of the model combining the data of the representative and laboratory samples. The conditioning vector $x$ in the first specification contains a constant term and a dummy variable LAB equal to 1 for observations in the laboratory student sample and 0 otherwise. In line with the previous descriptive results, amounts invested are significantly lower in the student sample. The second specification adds controls for observable characteristics of participants, previous life experiences when trusting others (TRUSTEXP), and the subjective beliefs about the expected investment made by other players (SNORMS) ${ }^{18}$ The difference between the student and the representative samples captured by the LAB variable is no longer significant once we control for differences in observable characteristics, suggesting that differences in the background characteristics of players explain the better part of the difference in behavior in both samples.

Both the linear and quadratic terms in age are significant, indicating an inverted$\mathrm{U}$ relation between age and investments in social capital, with the propensity to invest reaching its maximum at 37 years of age. ${ }^{19}$ This reconfirms the invertedU shape pattern usually found in the social capital literature (e.g., Putnam, 2000; Alesina and La Ferrara, 2002) and is also consistent with age profiles estimated using

\footnotetext{
${ }^{18}$ We have experimented with a specification including cross-terms but none was found to be statistically significant.

${ }^{19}$ Because we are using a cross-section, the age effect could also be a cohort effect, the two cannot be distinguished here.
} 
measures of community involvement (Glaeser, Laibson, and Sacerdote, 2002).

Women (FEMALE) invest significantly more than men, a finding which departs from laboratory experiments using the investment game. Those studies find that men either invest relatively more than women (e.g., Chaudhuri and Gangadharan, 2002; Buchan, Croson, and Solnick, 2003), or no significant differences in amounts invested between both sexes (Croson and Buchan, 1999). When restricting ourselves to the laboratory sample only (not reported in the table), average investments of women still exceed those of men, but the difference is no longer significant ( $p$-value $=0.555)$.

Economic status, reflected through employment status and personal income, does not have a significant effect on investment decisions. We do not find any effects of retirement status (RETIRED) on investment decisions, conditional on age. This observation is in contrast to Fehr, Fischbacher, Rosenbladt, Schupp, and Wagner (2003) who do not find any effects.

Our results indicate that individuals with secondary, technical training, and university degrees are more likely to make higher investments than subjects with low education levels (the omitted category). These results differ to Alesina and La Ferrara (2002), where education effects seem to have a linear impact, and Fehr, Fischbacher, Rosenbladt, Schupp, and Wagner (2003) who find no effects.

Subjects were classified as either protestants, catholics, or atheists. We find no evidence that either catholics or protestants invest differently than atheists or individuals of other religions (the omitted category). These results are concordant to the Alesina and La Ferrara (2002) study, but in contrast to the Fehr, Fischbacher, Rosenbladt, Schupp, and Wagner (2003) study who find a positive effect for catholics. 
Interestingly, past experiences when trusting others (TRUSTEXP) do not have a significant effect on social capital investments. This result does not support the prediction of the indirect evolutionary approach to adaptation through experience literature (for a recent survey see Ostrom, 2000) which suggest that someone's social investment behavior is directly related to his past experiences. Some experiments have looked at how past experimental decisions and outcomes in multiple period investment games influence current period decisions (e.g., Engle-Warnick, 2004). The type of past experiences we measure here is complementary, as it covers lifetime experiences with trust rather than their experiences in the more recent experimental periods.

Individuals with higher expectations about the level of investments made by other senders (SNORMS) invest significantly more than senders with lower expectations, which corroborates the presence of social norms geared at increasing efficiency and social cooperation.

Endogeneity of our social norms variable is a potential concern if participants conditioned their subjective expectation statements on their investment decisions. Such conditioning could result for example from subjects stating expectations in an attempt to rationalize their investment decisions. We test our model specification using the statistic proposed by Butler and Chatterjee (1997). Under the null hypothesis of normality of the error term $\varepsilon_{i}$ and exogeneity of the model regressors $\mathbf{x}_{i}$, the Butler and Chatterjee test is distributed chi square, with degrees of freedom being a function of the number of outcomes of the categorical variable $I$, the dimension of the vector $\mathbf{x}$, and the number of model parameters. ${ }^{20}$ Test values and associated

\footnotetext{
${ }^{20}$ In particular, let $\left\{d_{k i}\right\}_{k=1}^{K-1}$ be a sequence of binary variables, with element $d_{k i}$ taking a value of
} 
$p$-values are reported at the bottom of Table 2 . We find that the null hypothesis is not rejected at conventional levels, suggesting a correct model specification.

In order to check whether pooling both samples influences our estimates, we reestimated the second specification omitting the student sample. Results of this exercise are presented in the third column of Table 2 . We find that results are relatively insensitive to the inclusion of the student lab sample, with all parameter estimates keeping their sign and degree of significance, an indication that the relatively small sample size and the relatively small variation in observable characteristics of the lab sample do not contribute greatly to identify the model parameters.

\section{Inferences using WVS trust question as a proxy}

Measuring social capital using experiments is difficult when the target group is a nation's population. A more accessible alternative consists of surveying a population and asking direct questions on intended behavior. The WVS trust question has been used by a number of researchers to proxy for social capital (e.g., Alesina and La Ferrara, 2002). We focus here on whether the effect of background characteristics found above can also be obtained by using answers to the WVS trust question.

In order to compare our experimental results to those obtained using survey questions, the CentERpanel asked a large sample of panel members who did not $\overline{1 \text { when } I_{i}=k \text { and } 0 \text { otherwise. Denote }}$ by $\mathbf{m}_{i}$ the $(K-1) \times 1$ vector of stacked moments where the $j$ th element is given by $\sum_{i=1}^{N}\left(\mathbf{x}_{i}\left(d_{j i}-\operatorname{Pr}\left(I_{i}=j \mid \mathbf{x}_{i}\right)\right)\right)$. The Butler and Chatterjee (1997) test statistic is based on the quadratic form $N \cdot \mathbf{m}_{i}^{\prime}\left(\mathbf{V}_{i}^{-1}\right) \mathbf{m}_{i}$ with $\mathbf{V}_{i}=\mathbf{m}_{i} \mathbf{m}_{i}^{\prime}$, evaluated at the parameter estimates of the ordered probit model. Under the null hypothesis that $\varepsilon_{i}$ is normally distributed and that the vector $\mathbf{x}_{i}$ is exogenous, this statistic is distributed chi square with $\left[\operatorname{dim}\left(\mathbf{x}_{i}\right)-1\right] \cdot(K-2)$ degrees of freedom. 
participate in the experiment to answer the following question

WVS trust question Generally speaking would you say that most people can be trusted or that you cannot be too careful in dealing with people?

1.) Most people can be trusted.

2.) You have to be very careful.

3.) I do not know.

Given the strong link between our experiment and the WVS question, it was crucial that these panel members did not play the experiment. This overcomes the problems of having had the experiment either before or after the survey question influence either responses. We collected answers to this question from 2191 panel members in October 2002. Descriptive statistics of this new sample (the column "WVS survey participants" of Table 1) indicate that the composition of this new sample is relatively identical to that of the experimental sample used above.

We follow the popular trend (Alesina and La Ferrara, 2002) of grouping in a single category individuals reporting not knowing whether they trust with individuals who do not report trusting others. Based on this aggregate measure, $50.5 \%$ of respondents stated not trusting others. The last two columns of Table 2 report the results from a probit regression of answers to this survey question on background characteristics of the panel members. The differences with the experimental estimates are quite remarkable. First, we do not find any effect of education on survey trust, while low educated individuals invest relatively less in the experiment. A second noticeable difference with the experimental measure is gender, with women more likely to state that they trust others. Women were found to make significantly 
lower investments than men in the experiment. Other notable differences are that positive past experiences with trust and higher gross personal income now have positive and significant effects on the probability of stating to trust others, while no such effects were found in the experiment. Finally, the inverted-U shape effect of age is still present using survey trust, while economic status variables such as income and work do not correlate with stated trust.

\subsection{Empirical Results on Rewards to Investment}

The individual level analysis of the return ratio $R_{a i}$ is based on the following Tobit model

$$
\begin{aligned}
R_{a i}^{*} & =\gamma_{0}+\gamma_{1} a+\gamma_{2} a^{2}+z_{i}^{\prime} \boldsymbol{\eta}+\left(a \cdot z_{i}\right)^{\prime} \boldsymbol{\alpha}_{1}+\left(a^{2} \cdot z_{i}\right)^{\prime} \boldsymbol{\alpha}_{2}+\epsilon_{i} \\
R_{a i} & =R_{a i}^{*} \quad \text { if } R_{a i}^{*}>0 \\
& =0 \quad \text { if } R_{a i}^{*} \leq 0
\end{aligned}
$$

where equation (3) describes an individual's latent propensity to reward investments, and equations (4) and (5) describe the censoring rule which allows responders with extremely low propensities to return nothing with positive probability. Like for the case of investments, the return propensity is modelled as a function of the amount invested by the sender, i.e., $a \in\{0,50, \ldots, 500\}$, background characteristics $z_{i}$, the vector of unobservable parameters $\eta$, and an unobservable component $\epsilon_{i} \sim N\left(0, \sigma^{2}\right)$. The quadratic form in $a$ is added to capture the monotone increasing shape of proportions returned. ${ }^{21}$ We interact the quadratic form of $a$ with the ob-

\footnotetext{
${ }^{21}$ We have estimated a less restrictive specification with dummy variables for each $a$ category. Results were numerically identical to those presented above.
} 
servable characteristics to allow return ratio vectors to differ across individuals both in terms of levels and slopes.

We estimated two specifications grouping both the representative and the lab samples. The first included only the dummy variable LAB for decisions made in the laboratory and its interaction with the quadratic form in $a$. The second specification added controls for background characteristics, with all variables interacted with the quadratic form in $a$. In light of the relatively high number of parameters, and that most variables did not have a significant effect on the slope of the return ratio vectors (their corresponding elements of $\alpha_{1}$ and $\alpha_{2}$ were not statistically different from zero), Table 3 reports the regression results keeping only the interaction terms which were significant.

Results from the first specification confirm the descriptive analysis of the previous section, namely that the average return ratio vector is increasing and concave in $a$, and that return ratios are significantly lower in the student sample compared to the representative sample. The insignificance of both interaction terms of the LAB variable with the quadratic form in $a$ suggest that differences in average return ratios between both samples are relatively constant over all possible levels of investments.

Like for the case of investments, we find that the magnitude of the LAB variable diminishes and is no longer significant once we add controls for background characteristics, suggesting that differences in observable characteristics explain most of the discrepancies between both samples. A log-likelihood ratio test $\left(\chi_{29}^{2}=349.34, p\right.$ value $=0.000$ ) clearly prefers the model with controls for observable heterogeneity in the population.

Several variables have a significant impact on the level of the return ratio vector 
but not on its slope. We find that women return relatively more than men, and low educated individuals (the omitted category) return relatively more than higher educated persons, most of these differences being either significant or close to being significant at the $5 \%$ level. These patterns are contradictory to those of investment behavior, where all these variables had a significant but opposite effect on investment decisions. We discuss this issue in more detail in the following section.

The impact of responders' beliefs about the investment they thought they would receive (RTHINK) only enters significantly (at the 10\% level) when crossed linearly with $a$, which means that the positive effect on the return ratio of expecting higher investments increases with the amount invested.

Age is the only variable with both a significant effect on the level and the slope of the expected return ratio vector. Due to the number of parameters involved, it is difficult to fully grasp the age patterns by looking only at the parameter estimates, most of which are significantly different from zero and of different signs. We instead comment on their effects by plotting the predicted expected return ratio conditional on age for regularly spaced investments of 0 CP, $100 \mathrm{CP}, 200 \mathrm{CP}, 300 \mathrm{CP}, 400 \mathrm{CP}$, and $500 \mathrm{CP}^{22}$ We fix the level of the expected return ratio vector by setting all characteristics of the return propensity equation (3), except age, at their sample average. ${ }^{23}$ Figure 3 presents the predicted age profiles. There are two striking aspects to this graph. First, there is strong U-shape relation between the propensity to reward and age for investments between 0 and $200 \mathrm{CP}$, with the expected return ratios reaching

\footnotetext{
${ }^{22}$ We make use of the fact that the conditional expectation of $R_{a}$, censored at zero, is equal to $\mathbf{E}\left(R_{a} \mid \mathbf{z}, a\right)=\left(\mathbf{E}\left(R_{a}^{*} \mid \mathbf{z}, a\right)+\sigma \cdot \lambda(z, a)\right) \cdot \operatorname{Pr}\left(R_{a}^{*} \geq 0 \mid \mathbf{z}, a\right)$, where $\lambda(\mathbf{z}, a)$ denotes the inverse Mills ratio. ${ }^{23}$ What we set these variables at matters mostly for the level of the simulations, and not the slopes of the age profiles.
} 
a minimum in the range of 35 and 40 years of age, close to the turning point of the inverted $U$ relation between investments and age discussed in the previous section. The U-shape pattern flattens out progressively as levels of investment increase but remains convex over the age domain.

As in the case of the investment decision, measures of economic status such as whether an individual works or personal gross income do not correlate significantly with the return decision. Religion and past experiences with trust also do not have significant effects on the response behavior. Finally, the last two columns of Table 3 reports estimates of the second specification using only the representative sample data. Again, we find very little differences in either sign of significance of parameter estimates.

\section{Discussion of asymmetries}

The previous section has provided evidence that the heterogeneity in investment and reward behavior is significantly related to observable characteristics of participants. This relation was found to be characterized by some surprising asymmetries. In particular, keeping other factors constant, men and low educated individuals make significantly lower investments, but reward investments significantly more. This pattern was also found to hold for the young and the old, at least for investments representing less than half of the senders' endowment.

Because the present paper is one of the first systematic exploration linking background characteristics of a random sample of a population with their experimental behavior, it is difficult to relate the age and education asymmetries to other exist- 
ing results. By far the easiest and most documented asymmetry we can relate to is that of gender. Croson and Buchan (1999) note that gender differences in the investment game tend to be conditional on the level of risk present in the experiment. In decisions where risk is present, such as the investment decision in our game, they find that the behavior of women and men does not systematically differ. On the other hand, for decisions involving no risk, such as responders in our game, women return significantly more. Our results do not support this explanation, as we find that women invest more than men despite the riskiness of the situation, while men return significantly more than women in the risk free role of responders, suggesting that gender effects are unlikely to be universal.

Another explanation could be that subgroups of the population react differently in the roles of senders and responders because the benefits and costs of sending money to the other party, possibly out of pure altruism, differ between senders and responders. In our game, senders need only to forego $50 \mathrm{CP}$ to transfer $100 \mathrm{CP}$ to the other party, as investments were multiplied by two, while responders had to tradeoff one to one to transfer back to investors. Andreoni and Vesterlund (2001) for example find that men are more altruist when the costs of altruism is low, while women are more altruist when the cost of being altruist is high. Quite to the contrary, our gender effects indicate that women send significantly more than men when cost of altruism are relatively low (in the investment decision), but men send relatively more when the cost of altruism are relatively high (in the responders decision). ${ }^{24}$

\footnotetext{
${ }^{24}$ Our game differs from dictator games used by Andreoni and Vesterlund to measure altruism because trust and trustworthiness are also intrinsic and perhaps the most prevalent motive for in-
} 
Some support for this hypothesis can be obtained by comparing our results to those of Fehr, Fischbacher, Rosenbladt, Schupp, and Wagner (2003). In their design, both amounts invested and amounts returned were doubled, thus in effect equalizing the costs of sending money to the other party across both roles. ${ }^{25}$ Their regression results do not support the presence of significant asymmetries in investment and reward to investment behavior across the German population. ${ }^{26}$ These and our results suggest that asymmetry in the incentive structure of the game may be an important aspect in explaining asymmetries in investment and reward behavior.

\section{Conclusion}

Societies are composed of heterogeneous individuals who differ in terms of their socio-economic characteristics and, possibly in terms of their propensities to trust, reciprocate, or to be altruist. Because societies change and because of the well documented link between social capital and economic efficiency, recovering the link between the heterogeneity in observable characteristics and heterogeneity in propensities of individuals to enhance and sustain social capital becomes increasingly imvesting and rewarding investments in our experiment.

${ }^{25}$ Our design differs from theirs in several other ways. First, their experiment is performed after face-to-face interviews conducted for the German Socio-Economic Panel. Second, they use an environment of immediate response rather than the strategy method to collect the reward decisions of responders.

${ }^{26}$ They find that individuals 65 years and older invest relatively less but reward investments relatively more than individuals below 35 years of age, while immigrants invest relatively more but reward investments relatively less than natives. Both asymmetries are, however, only significant at the $10 \%$ level. 
portant. This study presented results from a computerized experiment combining the strengths of experiments and survey data collection methods which allowed us to collect data on investment and reward behavior for a random sample of individuals drawn from the Dutch population. The different inferences we obtained using answers to a survey question on trust, which is widely used as a proxy for social capital, indicates the importance of combining experimental and survey methods in order to allow heterogeneous participants to reveal rather than state their propensities to provide and sustain social capital.

The first important set of results was that the heterogeneity in propensities to invest and to reward investments in the Dutch population can be linked to several important socio-economic characteristics such as age, education, and gender. Equally important, this heterogeneity in behavior was shown to be characterized by previously undocumented asymmetries. In particular, holding other factors constant, men, low educated individuals, and the young and the old were respectively found to make significantly lower investments, but reward significantly more. These results have important implications as they suggest that communities, because of the homogeneous socio-economic composition of their habitants, may have a relatively higher propensity to invest and a relatively lower propensity to reward these investments, and hence provide relatively lower incentives to invest than other communities. In terms of education for example, our results suggest that keeping other factors constant, the propensity to invest is higher in groups of high educated individuals than in groups of low educated individuals, but the propensities to reward investments are higher in the group of low educated individuals than in the group of high educated individuals. Because the experiment presented here was static and 
involved interaction between strangers, we are unable to make inferences on the dynamic evolution of the possible tensions between the willingness to invest and the incentives to do so if individuals interact together for longer periods of time. Nevertheless, we think our results suggest the need for such investigations.

A second important result is that social norms seem to have played an important role in determining investment behavior in our experiment, with senders investing more the more they thought other senders would. Also, whether subjects had good or bad past lifetime experiences when trusting others has no significant impact on their investment and reward behavior in our experiment.

A third result is that the behavior observed in our laboratory sample differed significantly from that in our representative sample, with lab participants making significantly lower investments, and rewarding significantly less than participants in the representative sample. We showed that differences in the observable composition of both samples account for most of the observable differences in behavior. Despite these differences, the laboratory sample was nevertheless informative of the behavior in the Dutch population in the sense of providing a lower bound on the levels of investments and on the propensities to reward investments. Similar lower bounds were found by Gächter, Herrmann, and Thöni (2004) for public good games, which indicates that such results may also hold for different populations and social dilemma games. This finding indicates that trust, trustworthiness and other social preferences, once identified in the lab, are likely to be present, and in more important forms in the population as a whole. These results are encouraging as they suggest that laboratory experiments may serve as an important first step to identify population levels of existing and new forms of economic primitives and preferences 
of individuals.

\section{A Instructions (Translation)}

The first 3 screens of the experiment are the same for both senders and responders. Italic notes in the translation are comments by the authors.

- First screen:

This experiment is a research project of researchers from Humboldt University Berlin and Catholic University of Brabant. ${ }^{27}$

With this experiment you can make real money in terms of CentERpoints. You receive from the researchers additional CentERpoints (besides the usual telephone allowance).

- Second screen:

During this experiment you will be matched with another member of the panel. You will not know who this person is, both of you will stay anonymous. Both of you receive 500 CentERpoints. Then the experiments starts.

One of you has the possibility to send a share of this away. The amount of points sent will be doubled and given to the other person. The other person has then the opportunity to send a share of the own total amount back. The amount which is sent back will not be doubled.

How many points you finally earn depends therefore on your decision and the decision of the person you are matched with. You will be randomly assigned to your role.

\section{- Third screen:}

We now give you the chance to indicate whether you want to participate. If you decide not to participate, the experiment will end immediately. You will receive the usual telephone reimbursement. If you continue you will receive the 500 CentERpoints.

\footnotetext{
${ }^{27}$ Now: Tilburg University. The Catholic University of Brabant changed its name after the experiment.
} 
Do you want to continue?

Yes

$\bigcirc$ No

Subjects who choose to participate were then randomly assigned to their roles. Senders and receivers had to read decision screens tailored to their roles.

Senders

- Fourth screen:

You have been matched with another member of the panel. Like you, this person received 500 CentERpoints. You can send a share of your 500 CentERpoints. The panel member with whom you are matched with receives the amount you sent multiplied by 2. Then, this person has the opportunity to send a share of the own total amount back (without knowing who you are). The amount which this person sends back to you will not be doubled.

How many points do you want to give?

(The sender could send one out of 11 possible amounts.)

$\bigcirc 0$ the other person receives additionally nothing and has therefore 500 and you remain with 500 points.

$\cdots$

500 the other person receives additionally 1000 and has therefore 1500 in total and you remain with 0 points.

- Fifth screen:

(was depending on the decision taken at the fourth screen, here as example "200")

You decided to send 200 CentERpoints.

The panel member you are matched with receives therefore 400 additional CentERpoints.

He or she has therefore in total 900 CentERpoints.

You remain with 300 CentERpoints.

How many points do you think the other panel member with whom you are matched with will send to you?

(Participants had to type in a number. In this example in the range of $[0,900]$.) 
- Sixth screen:

This experiment is done with some panel members. Half of them interact in the same position as you. They can send a share of their 500 CentERpoints which is doubled and received by a person of the other position.

How many points do you think those panel members have sent?

(The sender could indicate one out of 11 possible amounts from 0 to 500).

\section{Responders}

- Fourth screen:

You have been matched with another member of the panel. Like you, this person received 500 CentERpoints. This person is asked to send you a share from their own 500 CentERpoints. You will receive the amount of those points the other person has sent multiplied by 2 .

For example, if the other person sends 100 CentERpoints, you will receive 200 CentERpoints. Together with the 500 points you begin with, you will have in total 700 CentERpoints.

From this amount you can return a share. The amount you send will not be doubled.

- Fifth screen:

As we do not know now how many CentERpoints the other panel member with whom you are matched with has sent we present all possible amounts this person could send to you. The amount you receive is written in the next column. Please indicate in the last column what amount you would return for each possible amount sent.

After the real decision of the other person is known the amount you indicated for this particular decision will be realized. The amount you will return will be deducted from your total amount.

(The responder had to indicate for each of 11 possible amounts the sender could send what he would return. The table was designed as follows:) 
If the other sends: I receive: In total with the In this case I return: 500 CentERpoints:

0

500
0

1000
500

1500 .

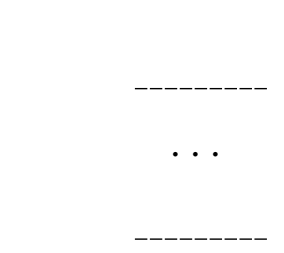

- Sixth screen:

How many points do you expect the panel member with whom you are matched with has sent to you?

(The responder could indicate one out of 11 possible amounts from 0 to 500.)

After these screens the experiment was over. Nobody could go return to a previous screen from the experiment. Senders and responders were asked the following post-experimental questions:

- Seventh screen (Trust experience question):

The last two questions are about trust in general. This question is about your own trust experience.

If you trust is your trust generally rewarded or exploited?

Choose the number which is closest to your answer.

always rewarded 1234567 always exploited.

(Participants had to type in a number between 1 and 7 . For the data analysis we inverted the order, that higher numbers are associated with more positive experience, i.e. we recoded 1 by 7 and so on: always exploited 1234567 always rewarded.)

- Eight screen (WVS trust question):

Generally speaking would you say that most people can be trusted or that you cannot be too careful in dealing with people?

1.) Most people can be trusted.

2.) You have to be very careful.

3.) I do not know. 


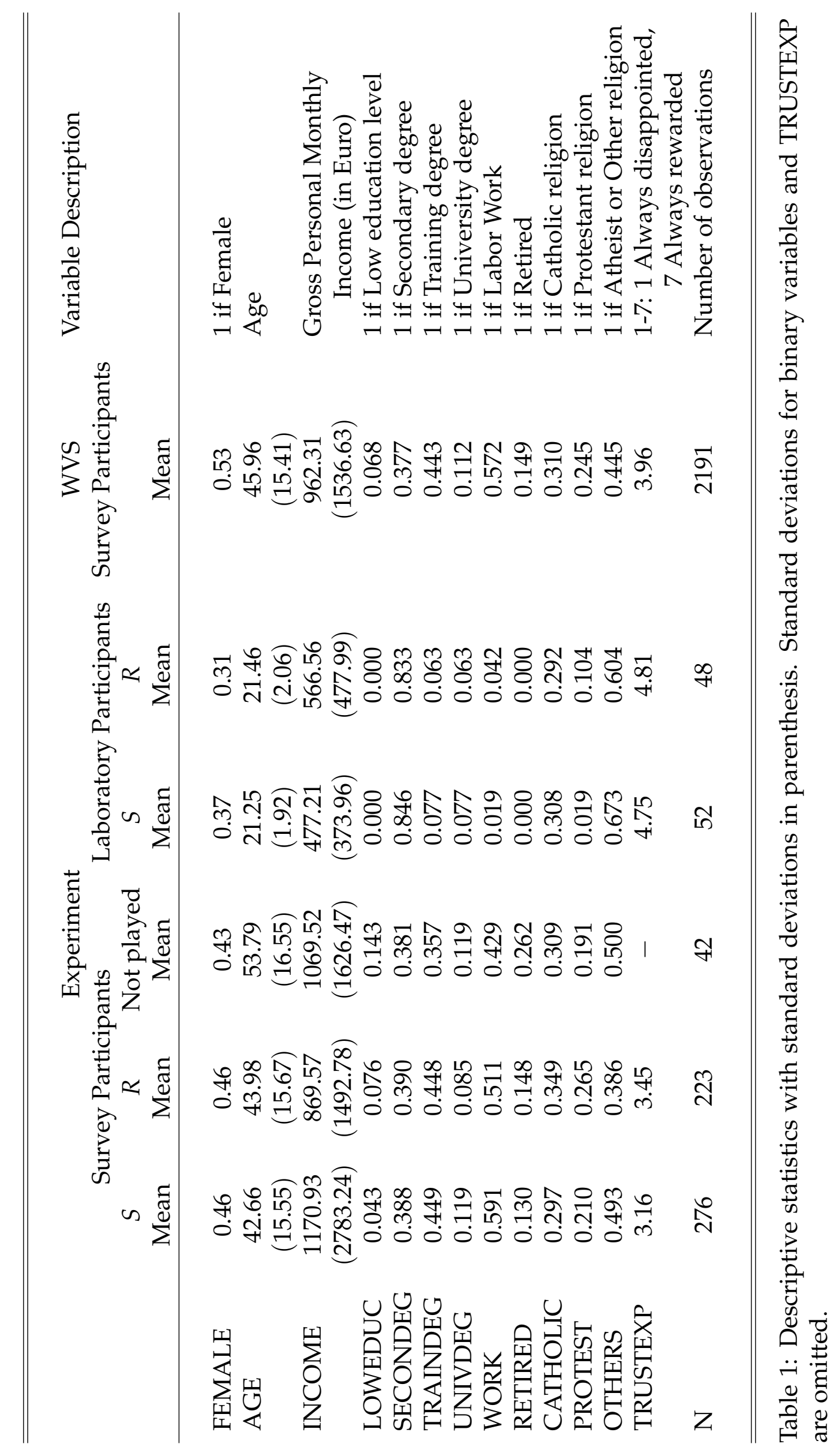




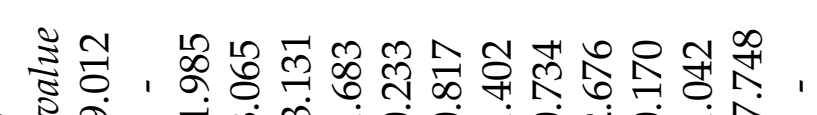
舟市

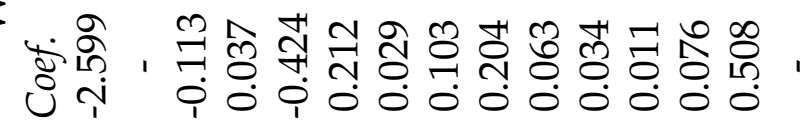

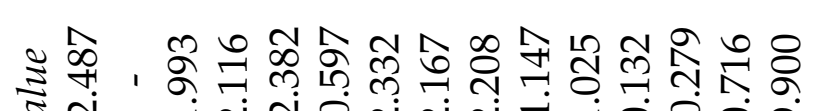
गु

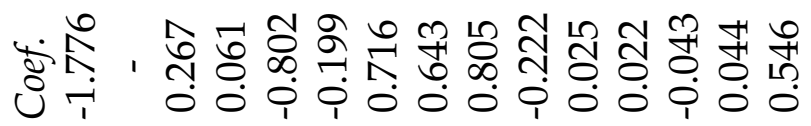
芉

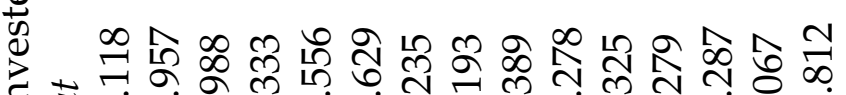

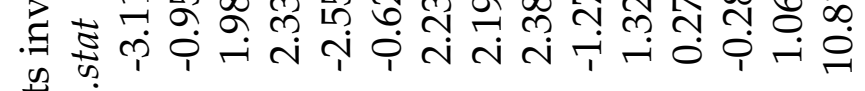

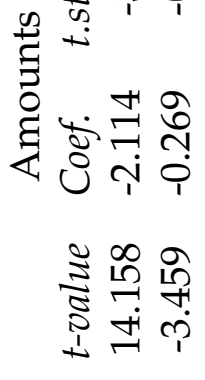

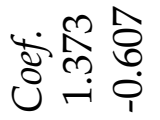

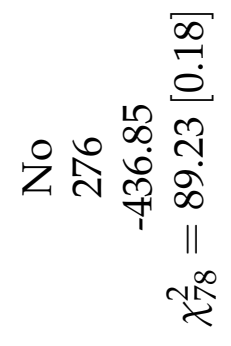

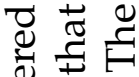

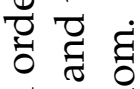

वี छ

bo:

की के

월

要

오 ․․ 3

घี 동

పै

苞焉

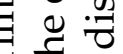

过

당

$\pm$

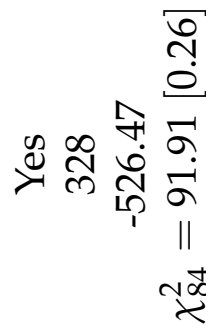

.

可

\&

표

步

齿

वै के

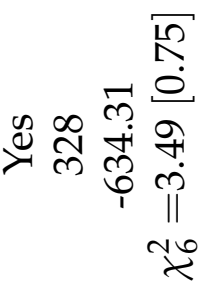

둥효

表示

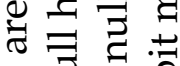

क 르

.

त्ष

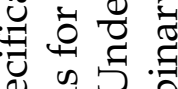

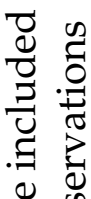

. 5

के पू

ક

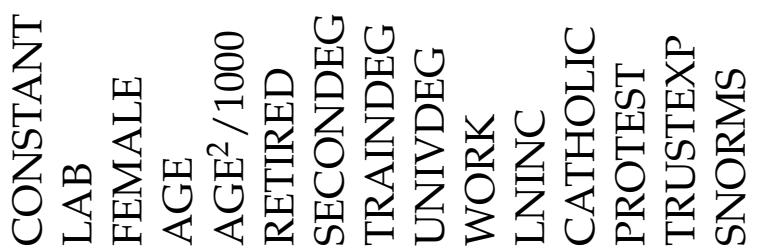

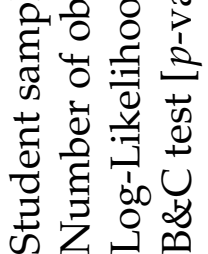

䓹壳

工 屯

ग्ञ $\vec{\Xi}$

ㅈ․․․․

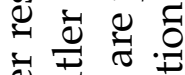

过泀

के है

त 5 के के

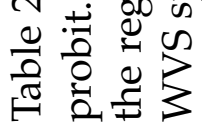




\begin{tabular}{|c|c|c|c|c|c|c|}
\hline \multirow[b]{3}{*}{ CONSTANT } & \multicolumn{6}{|c|}{ Return ratio } \\
\hline & Coef. & t-value & Coef. & t-value & Coef. & t-value \\
\hline & -0.063 & -4.607 & 0.257 & 3.128 & 0.247 & 2.833 \\
\hline$a$ & 0.088 & 17.759 & 0.011 & 0.477 & 0.008 & 0.320 \\
\hline$a^{2}$ & -0.005 & -11.844 & -0.001 & -0.597 & -0.001 & -0.582 \\
\hline LAB & -0.096 & -3.258 & -0.068 & -1.547 & - & - \\
\hline $\mathrm{LAB} \times a$ & 0.001 & 0.101 & -0.007 & -0.449 & - & - \\
\hline $\mathrm{LAB} \times a^{2}$ & -0.0002 & -0.275 & 0.0002 & 0.191 & - & - \\
\hline FEMALE & & & -0.044 & -1.947 & -0.051 & -1.861 \\
\hline AGE & & & -0.013 & -4.718 & -0.011 & -4.207 \\
\hline $\mathrm{AGE}^{2} / 1000$ & & & 0.161 & 5.374 & 0.146 & 4.829 \\
\hline RETIRED & & & -0.013 & -0.775 & -0.006 & -0.376 \\
\hline SECONDEG & & & -0.104 & -1.980 & -0.098 & -1.891 \\
\hline TRAINDEG & & & -0.081 & -1.823 & -0.072 & -1.789 \\
\hline UNIVDEG & & & -0.141 & -2.456 & -0.136 & -2.201 \\
\hline WORK & & & 0.017 & 2.129 & 0.011 & 1.356 \\
\hline LNINC & & & 0.002 & 1.479 & 0.002 & 1.615 \\
\hline CATHOLIC & & & -0.002 & -0.456 & -0.009 & -1.224 \\
\hline PROTEST & & & 0.002 & 0.231 & 0.003 & 0.478 \\
\hline TRUSTEXP & & & -0.011 & -1.033 & -0.014 & -1.157 \\
\hline BTHINK & & & 0.003 & 0.728 & 0.003 & 0.662 \\
\hline $\mathrm{AGE} \times a$ & & & 0.002 & 5.633 & 0.003 & 6.295 \\
\hline $\mathrm{AGE}^{2} / 1000 \times a$ & & & -0.028 & -5.472 & -0.032 & -6.116 \\
\hline $\mathrm{AGE} \times a^{2}$ & & & $-9.37 E-5$ & -9.783 & -0.0001 & -11.217 \\
\hline $\mathrm{AGE}^{2} / 1000 \times a^{2}$ & & & 0.001 & 4.719 & 0.001 & 5.329 \\
\hline$\sigma^{2}$ & & & 0.021 & 23.334 & 0.021 & 22.11 \\
\hline Student sample included & & & $\mathrm{Y}_{\epsilon}$ & & $\mathrm{N}$ & $\mathrm{O}$ \\
\hline Number of observations & 29 & & 29 & & 24 & 53 \\
\hline Log-Likelihood & 862 & 13 & 103 & 80 & 939 & .83 \\
\hline
\end{tabular}

Table 3: Responder results - Tobit estimator. The t-statistics are based on robust standard errors. Only the significant interactions of variables with $a$ and $a^{2}$ are reported in the second and third specifications. Other interaction terms were included in the regressions but are omitted from the table. 
B Figures

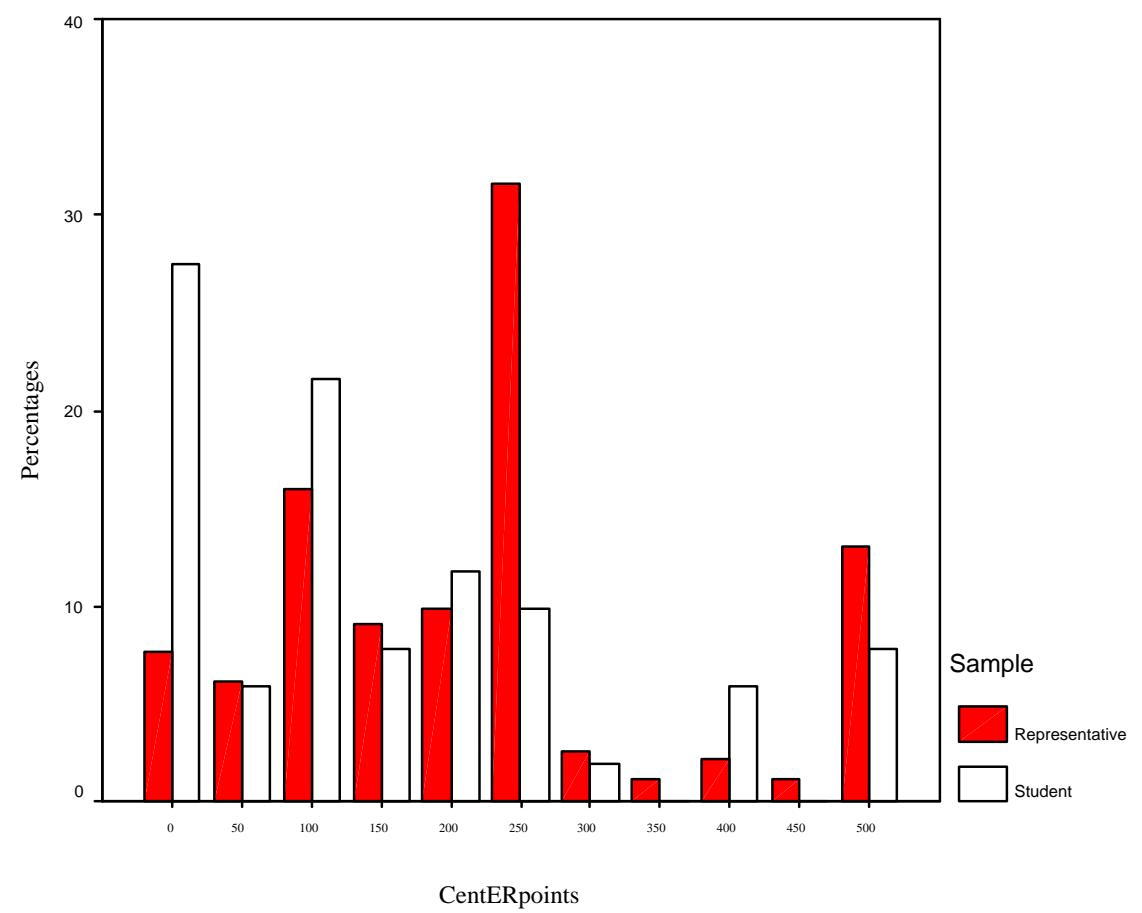

Figure 1: Distribution of amounts invested in the representative and students samples. 

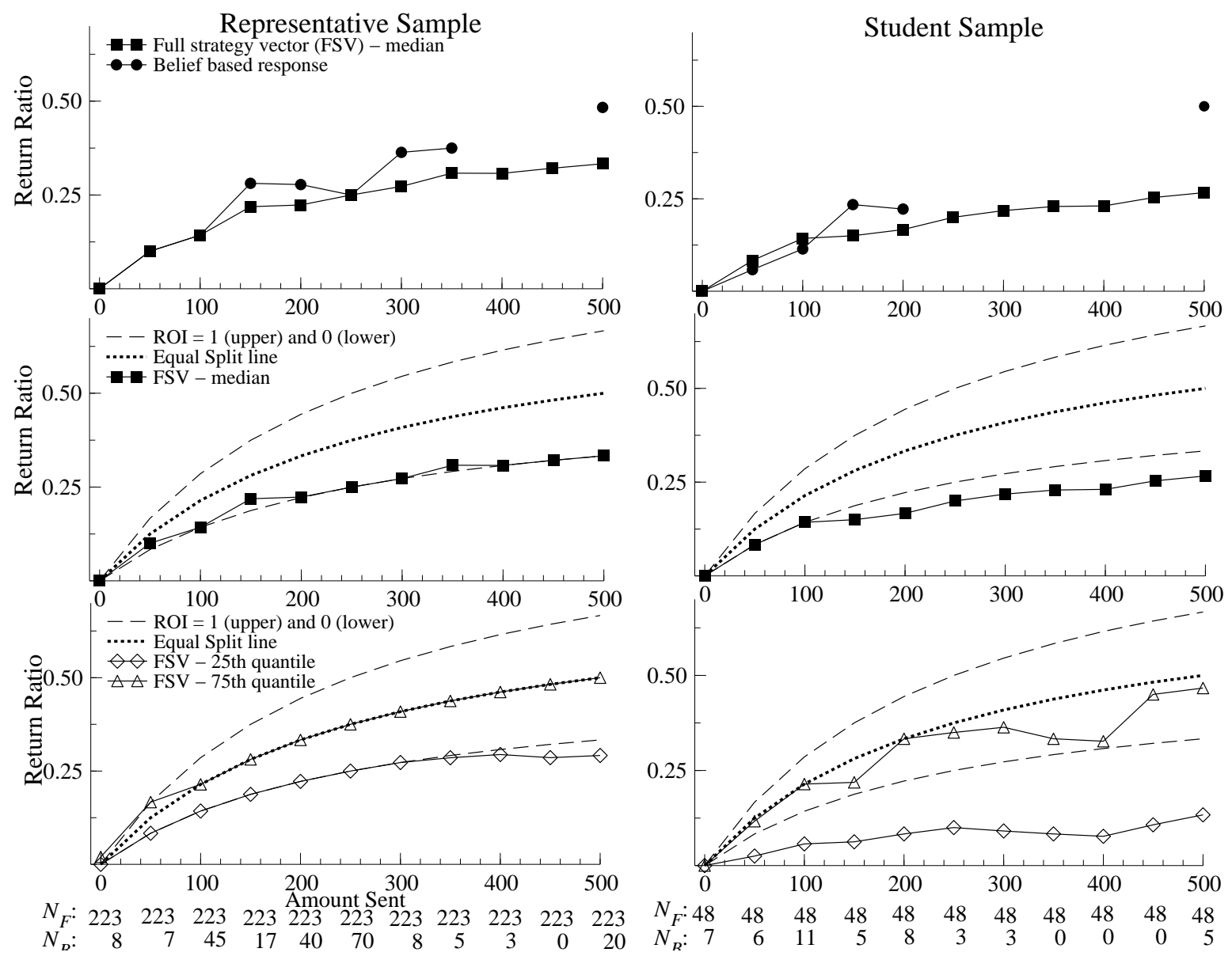

Figure 2: Top row presents the median return ratio in the representative and the student samples for each possible amount received using the full strategy vector response data (square line). Circle line presents the median return ratio using only the element of the strategy vector corresponding to the amount responders believed they would be offered. Middle and bottom rows plot visual aids to understand response behavior in the representative and student samples. The lower (upper) dashed lines represent the return ratio providing senders with a return on investment ((Amount returned - Amount sent)/ Amount sent) of 0 (1). The dotted lines represent the return ratio providing senders and responders with equal monetary payoffs. The middle row plots the median return ratio for both samples. The lower row plots the 25 th and 75 th quantiles of the return ratio for both samples. $N_{F}$ denotes the sample size used to compute the return ratio for each outcome based on the full strategy vector, $N_{B}$ denotes the sample size used to compute the return ratio for each outcome based on their expectations. The sum of $N_{B}$ across all categories gives the sample size in both samples. In the later case, cells with less than 5 data points are not plotted. 


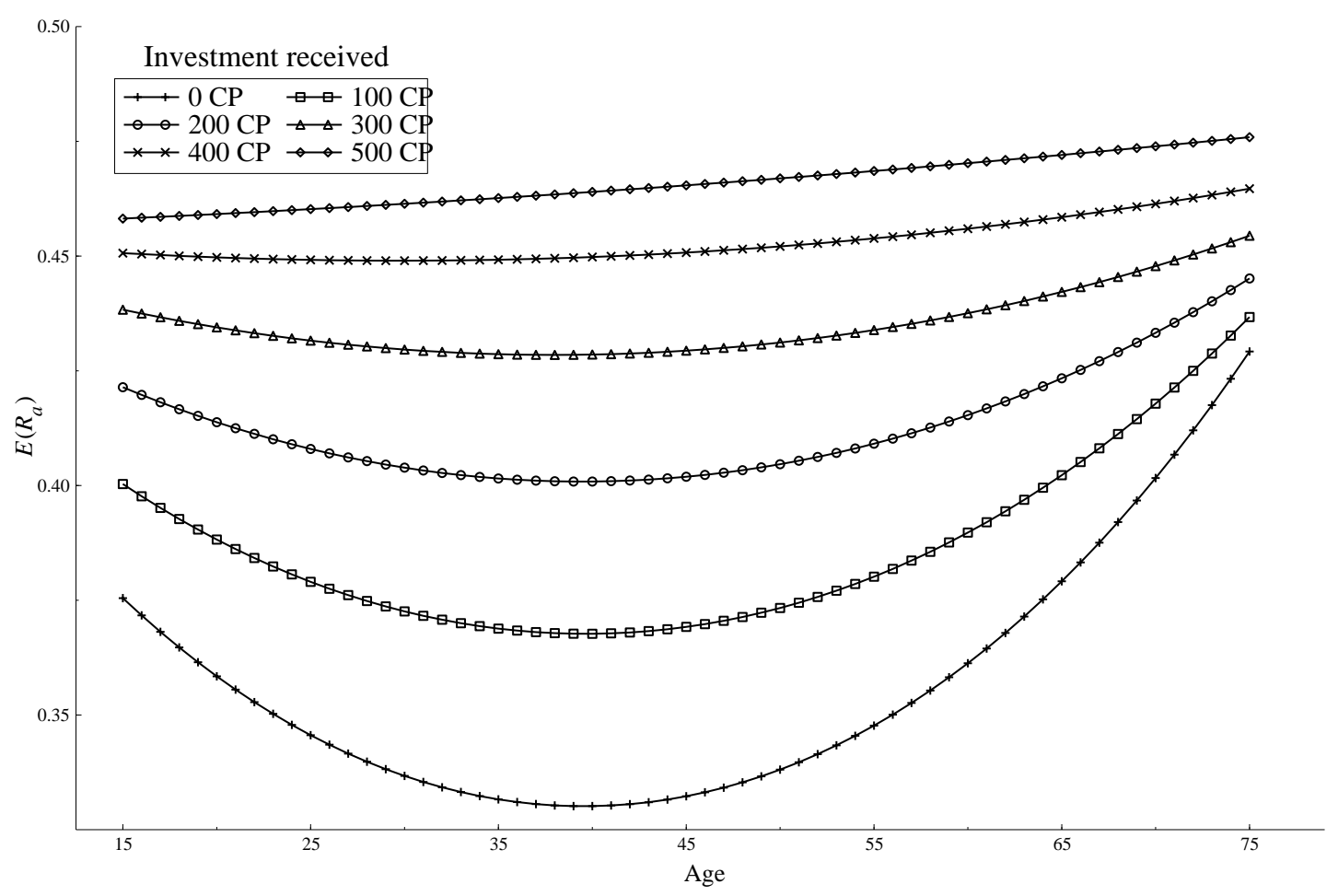

Figure 3: Predicted expected return ratio's by age and levels of investments received. Expected returns are evaluated at the sample means of all observable characteristics (except age). 


\section{References}

Alesina, A., And E. L. Ferrara (2002): "Who Trust Others," Journal of Public Economics, 85(2), 207-234.

AndReOni, J., AND L. Vesterlund (2001): “Which is the Fair Sex? Gender Differences in Altruism," Quarterly Journal of Economics, February, 293-312.

BerG, J., J. Dickhaut, And K. MCCABE (1995): “Trust, Reciprocity, and Social History," Games and Economic Behavior, 10, 122-142.

Bosch-Domènech, A., J. G. Montalvo, R. NAgel, And A. Satorra (2002): "One, Two, (Three), Infinity, ... : Newspaper and Lab Beauty-Contest Experiments," American Economic Review, 92(5), 1687-1701.

Bowles, S., AND H. GinTIS (2002): "Social Capital and Community Governance," The Economic Journal, 112(483), F419-F436.

BRAndTS, J., AND G. CHARness (2000): “Hot Vs. Cold: Sequential Responses and Preference Stability in Experimental Games," Experimental Economics, 2, 227-238.

Brock, W., AND S. DuRlauf (2001): Interactions-Based Modelsvol. 5, chap. 54, pp. 3297-3380. Elsevier, North-Holland.

Buchan, N., R. CROson, And S. Solnick (2003): “Trust and Gender: An Examination of Behavior, Biases, and Beliefs in the Investment Game," Working paper, University of Wisconsin.

Butler, J. S., AND P. ChatterJee (1997): “Test of the Specification of Univariate and Bivariate Ordered Probit," The Review of Economics and Statistics, 79(2), 343347.

Carpenter, J., A. Deniere, And L. Takahashi (2004): “Cooperation, Trust, and Social Capital in Southeast Asian urban Slums," Journal of Economic Behavior and Organization, 55, 533-551.

CHAUdhuri, A., AND L. GANGADHARAN (2002): “Gender differences in trust and reciprocity," Working paper, University of Melbourne.

Cox, J. C. (2004): "How to Identify Trust and Reciprocity," Games and Economic Behavior, 46, 260-281.

CROSON, R., AND N. BuCHAN (1999): "Gender and Culture: International Experimental Evidence from Trust Games," American Economic Review Papers and Proceedings, 89, 386-391.

ECKel, C., AND P. GRossman (2000): "Volunteers and Pseudo-Volunteers: The Effect of Recruitment Method on Subjects' Behavior in Experiments," Experimental Economics, 3, 107-120.

ELSTER, J. (1989): "Social Norms and Economic Theory," Journal of Economic Perspectives, 3(4), 99-117. 
ENGLE-WARNICK, J., AND R. L. SlONIM (2004): “The Evolution of Strategies in a Repeated Trust Game," Journal of Economic Behavior and Organization, 55, 553-573.

Fehr, E., U. Fischbacher, B. V. Rosenbladt, J. Schupp, and G. Wagner (2003): “A Nation-Wide Laboratory Examining trust and trustworthiness by integrating behavioral experiments into representative surveys," Working paper 141, University Zurich.

FEHR, E., AND J. A. LIST (forthcoming): “The Hidden Costs and Returns of Incentives - Trust and Trustworthiness among CEO's," Journal of the European Economic Association.

FRIEDMAN, D., AND D. W. MASSARO (1998): “Understanding variability in binary and continuous choice," Psychonomic Bulletin and Review, 5, 370-389.

GÄCHTER, S., B. HERMMANN, AND C. THÖHNI (2004): “Trust, voluntary cooperation, and socio-economic backgroung: survey and experimental evidence," Journal of Economic Behavior E Organization, 55, 505-531.

Glaeser, E. L., D. Laibson, and B. SAcerdote (2002): “An Economic Approach to Social Capital," The Economic Journal, 112(483), F437-F458.

Glaeser, E. L., D. Laibson, J. A. Scheinkman, And C. Soutter (2000): “Measuring Trust," Quarterly Journal of Economics, 115(3), 811-846.

Haigh, M., AND J. List (2005): “Do Professional Traders Exhibit Myopic Loss Aversion ?," Journal of Finance, 60(1), 523-534.

HARrison, G. W., M. I. LAU, AND M. B. Wiliams (2002): “Estimating Individual Discount Rates in Denmark: A Field Experiment," American Economic Review, 92(5), 1606-1617.

HeCKMAN, J. J. (1978): “Sample Selection Bias as a Specification Error," Econometrica, 47(1), 153-162.

HEY, J. D. (2002): "Experimental Economics and the Theory of Decision Making under Risk and Uncertainty," Geneva Papers on Risk and Insurance Theory, 27(1).

LaPorta, R., F. L. De Silanes, A. Shleifer, And R. W. Vishny (1997): “Trust in Large Organizations," American Economic Review, 87(2), 333-338.

LiST, J. A. (2004): "Young, Selfish and Male: Field Evidence of Social Preferences," The Economic Journal, 114, 121-149.

MANSKI, C. F. (1999): Identification Problems in the Social Sciences. Harvard University Press, Harvard, USA.

MCLEISH, K. N., AND R. OxOBY (2004): “Specific Decision and Strategy Vector Methods in Ultimatum Bargaining: Evidence on the Strength of Other-Regarding Behavior," Economics Letters, 84(5), 399-405.

NoRTH, D. (1990): Institutions, Institutional Change and Economic Performance. Cambridge University Press, Cambridge, U.K. 
Ortmann, A., J. Fitzgerald, And C. Boeing (2000): “Trust, Reciprocity, and Social History: A Re-Examination," Experimental Economics, 3, 81-100.

Ostrom, E. (2000): "Collective Action and the Evolution of Social Norms," Journal of Economic Perspectives, 14, 137-158.

Putnam, R. (2000): 'Bowling Alone: The Collapse and Revival of the American Community. Simon and Schuster, New-York.

SELTEN, R. (1967): Die Strategiemethode Zur Erforschung Des Eingeschränkt Rationalen Verhaltens im Rahmen Eines Oligopolexperimentspp. 136-168. J.C.B. Mohr (Paul Siebeck), Thübingen.

SONNEMANS, J., AND T. OfFERMAN (2001): "Is the Quadratic Scoring Rule Really Incentive Compatible?," Working paper CREED, University of Amsterdam.

Williamson, O. (1985): The Economic Institutions of Capitalism. Free Press, NewYork, U.S.A.

ZAK, P. J., AND S. KNACK (2001): “Trust and Growth," Economic Journal, 111(4), 295-321. 